\title{
STATIC MAGNETIC FIELD AFFECTS OXIDATIVE STRESS IN MOUSE COCHLEA
}

\author{
PIOTR POLITAŃSKI ${ }^{1}$, ELŻBIETA RAJKOWSKA², MAŁGORZATA PAWLACZYK-ŁUSZCZYŃSKA ${ }^{3}$, \\ ADAM DUDAREWICZ ${ }^{3}$, ANETA WIKTOREK-SMAGUR ${ }^{2}$, MARIOLA ŚLIWIŃSKA-KOWALSKA ${ }^{2,3}$, \\ and MAREK ZMYŚLONY ${ }^{1}$
}

\author{
${ }^{1}$ Nofer Institute of Occupational Medicine, Łódź, Poland \\ Electromagnetic Hazards Laboratory \\ ${ }^{2}$ Nofer Institute of Occupational Medicine, Łódź, Poland \\ Audiology and Phoniatrics Centre \\ ${ }^{3}$ Nofer Institute of Occupational Medicine, Łódź, Poland \\ Department of Physical Hazards
}

\begin{abstract}
Objective: It has been shown that oxidative stress plays an important role in development of noise induced hearing loss. Since static magnetic fields (SMF) exposure may alter dynamics of oxidative processes in the tissue, the aim of the study was to assess the influence of SMF on noise-induced alteration in the cochlear level of reactive oxygen species (ROS) and hearing thresholds. Materials and Methods: Auditory brainstem response (ABR), lipid peroxidation (LPO) levels, superoxide dismutase (SOD) activity and catalase activity were assessed in the cochlea prior to, and at five time-points over two weeks following exposure of C57BL/6 mice to $8 \mathrm{~h}, 119 \mathrm{~dB} \mathrm{SPL}, 4 \mathrm{kHz}$ octave band noise. Results: The ABR indicated no permanent functional damage due to noise exposure either for the $4 \mathrm{kHz}$ and $8 \mathrm{kHz}$ SMF-exposed group or for animals not exposed to SMF. However, significant differences in LPO level, catalase and SOD activity between animals exposed to noise and SMF and those exposed to noise only were observed. Conclusions: The results suggest that SMF causes an increase in ROS level in the cochlea after noise exposure and, at the same time, it speeds up activation of antioxidative enzymes.
\end{abstract}

Key words:

Static magnetic field, Noise, Reactive oxygen species, Mouse cochlea

\section{INTRODUCTION}

Oxidative stress in the cochlea is considered to play an important role in noise-induced hearing loss. The delayed production of free radicals in cochlea has been held responsible for the noise-induced long-term damage to hair cells which progresses over time, stabilizing two or more weeks after the insult. The maximal levels of reactive oxygen species (ROS) in the cochlea are observed 7-10 days after noise exposure [1,2]. One of several theories explaining this delay is based on the deficiency of ROS scavenging enzymes after initial noise exposure [3].
It has been also shown that electromagnetic fields and static magnetic fields (SMF) may change dynamics of oxidative processes [4]. It seems that SMF may affect radical pairs recombination kinetics both during exposure to noise (which causes formation of radical pairs) and thereafter (when the lipid or protein peroxidation processes are the main source of radical pairs). Nowadays headphones are one of the most common sources of SMF localized by definition very close to auditory organ. To our knowledge, no research on the effects of combined exposure to noise and SMF on the oxidative processes in the cochlea has been conducted so far. 


\section{MATERIALS AND METHODS}

\section{Animals}

C57BL/6 mice 10-12 weeks old were used for this study. Since ROS detoxification may differ depending on gender [5], only male animals were used. The mice were housed in groups of four per cage and maintained in a temperature-controlled room with a 12-h light/dark cycle (lights on at 7:00 AM), and allowed free access to food and water. Animal care was under the supervision of the Laboratory Animal Unit of the Nofer Institute of Occupational Medicine, Łódź, Poland. The experimental protocol was reviewed and approved by the 9th Local Bioethical Committee (56/LB385/2007).

\section{Experimental design}

For the purposes of this study we used 80 animals. For each time point $(1,3,5,7$ and 14 days beginning with the day after exposure) we used 16 animals divided into four equal groups:

- Group I - mice exposed to noise and to SMF,

- Group II - mice exposed to noise only,

- Group III - mice exposed to SMF only,

- Group IV - mice exposed neither to noise nor to SMF (control group).

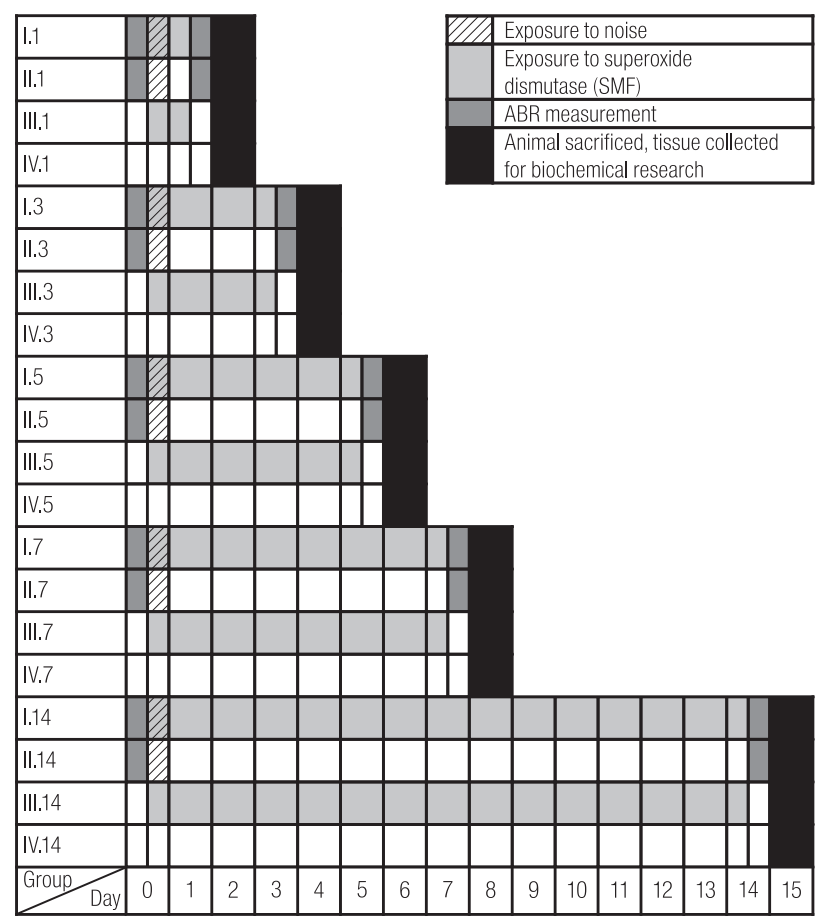

Fig. 1. Study design.
On the first day, noise and/or SMF exposure lasted for 8 hours and afterwards, until the last day of experiment, mice from groups I and III were exposed to SMF for 2 hours daily. The animals exposed neither to noise nor SMF were also placed in the same chambers as the exposed groups for the specified period, but without switching on the noise and/ or SMF generator, to ensure comparable distribution of any stress that might be experienced by the animals due to the experimental procedures. Prior to, and on the last day of exposure, auditory brainstem responses (ABR) were measured in the I and II group of animals. Tissue for biochemical analysis was harvested on the day following the last day of exposure to SMF (groups I and III) or on the corresponding day in the groups not exposed to SMF (groups II and IV). The details of study design are presented in Figure 1.

\section{Noise exposure}

Animals were kept in separate aluminum perforated cages (approx. $8 \times 8 \times 10 \mathrm{~cm}$ ) and exposed for 8 hours to $4 \mathrm{kHz}$ octave band noise $(\mathrm{OBN})$ at equivalent continuous sound pressure level of $119 \mathrm{~dB}(\mathrm{~A})$ in a ventilated sound exposure chamber [6]. The noise was generated using Sony Pictures Digital Sound Forge 8.0 software and delivered by a loudspeaker driven by the Sony type D-NE005 player and LANEY type CXP-115 active monitor to obtain diffuse acoustic field. The uniformity of distribution of sound pressure level within the exposure chamber was confirmed by multiple location measurements. Sound pressure level varied by a maximum of $3 \mathrm{~dB}$ across the measured sites within the chamber. The noise parameters during the exposure were monitored by a measuring system that consisted of the Bruel \& Kjaer type 4190 microphone, Svantek type SV03 microphone preamplifier and Svantek type SVAN 912 sound analyzer. The microphone was positioned within the cage at the level of the animal's head.

\section{SMF exposure}

Exposures to $5 \mathrm{mT}$ SMF were performed inside a pair of Helmholtz coils ( $35 \mathrm{~cm}$ diameter) which provided a highly homogenous field $( \pm 5 \%)$. For measurements of flux density (magnitude and distribution), a gaussmeter, model 9500 A, with STF 99-0404 probe (F.W.Bell, USA) 
was applied; the range of measurements was $3 \mu \mathrm{T}-30 \mathrm{~T}$, accuracy $\pm 0.1 \%$.

Animals from groups I and III were kept inside the coils during initial 8 hour exposure (group I simultaneously with the noise exposure) and thereafter 2 hours daily for the time of experiment (see Figure 1) in aluminum cages perforated for air and heat circulation.

\section{Auditory brainstem responses}

Auditoryevoked brainstem responses(ABR)were measured for both ears in animals exposed to noise (groups I and II) before noise exposure and at the time of experiment applicable for a given group (see Figure 1). Prior to the measurements, animals were anesthetized with intramuscular xylazine $(10 \mathrm{mg} / \mathrm{kg}$ ) and ketamine $(40 \mathrm{mg} / \mathrm{kg})$, and the external ear canal and tympanic membrane were inspected under an operating microscope. A differential active needle electrode was placed subcutaneously below the tested ear, a reference electrode at the vertex and a ground electrode was positioned just above the hind limb. The sound stimulus consisted of $12.5 \mathrm{~ms}$ tone bursts, with a rise-fall time of $1 \mathrm{~ms}$ at frequencies of $4 \mathrm{kHz}$, and $8 \mathrm{kHz}$ and was generated using an Audio Generator of RACIA Centor-O system. The stimuli were presented to the external auditory meatus and the sound intensity was decreased in 5-dB intervals. One thousand tone presentations, delivered at $10 / \mathrm{s}$, were averaged to obtain a waveform, using a data acquisition system and a microcomputer with RACIA software. Hearing threshold was defined as the lowest intensity of stimulation that yielded a repeatable waveform with an identifiable peak 1 or 2 . Both ears were examined simultaneously.

\section{Biochemical analysis}

Cochlear specimens were obtained from animals one day after the last day of exposure to SMF (group I and III) or the appropriate number of days for animals not exposed to SMF (group II and IV) and cochlea homogenate (whole cell extract) was prepared by grinding the dissected cochleae in $0.5 \%$ BHT in $20 \mathrm{mM}$ phosphate buffer, $\mathrm{pH}=7.4$. The homogenate was subjected to low-speed centrifugation at $3000 \mathrm{~g}$ for $15 \mathrm{~min}$ at $4^{\circ} \mathrm{C}$ and then used for all biochemical testing.
The protein content of the homogenate was determined by the Bio-Rad assay kit (BIO-RAD Lab.), with the bovine serum albumin as a standard. This kit, based on the Bradford dye-binding procedure, is a simple colorimetric assay for measuring total protein concentration.

\section{Lipids peroxidation (LPO) level}

The level of LPO was expressed as the amount of malondialdehyde (MDA) +4-hydroxynonenal (4-HNE), as major LPO end product. The amounts of MDA +4-HNE (in $\mu \mathrm{M} \times \mathrm{mg}^{-1}$ ) were determined with Bioxytech LPO-586 Assay kit (OxisResearch, Portland, OR).

\section{Catalase activity}

The activity of catalase in cochlear specimens (in $\mathrm{nM} \times \mathrm{min}^{-1} \times \mathrm{mg}^{-1}$ of $\mathrm{H}_{2} \mathrm{O}_{2}$ peroxidated with methanol to formaldehyde) was measured using a catalase assay kit (Cayman Chemical Company, Ann Arbor, MI).

\section{SOD activity}

The SOD activity in the cochlea was assessed by a SOD assay kit-WST (Dojindo Molecular Technologies, Inc., Gaithersburg, MD). Activity was calculated from a standard curve of purified bovine erythrocyte SOD (SigmaAldrich Co., St. Louis, MO, USA) and was expressed in

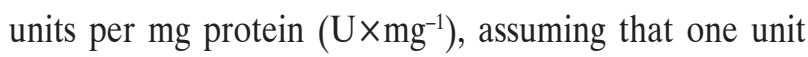
will inhibit reduction of cytochrome $\mathrm{c}$ by $50 \%$ in a coupled system with xanthine oxidase at $\mathrm{pH}=7.8$ at $25^{\circ} \mathrm{C}$ in a $3.0 \mathrm{ml}$ reaction volume.

\section{Statistical analysis}

All results of the biochemical analysis were normalized against given day's control group (group IV) for elimination of the casual errors.

$$
M_{n}=\frac{M}{M_{\text {av control }}},
$$

where:

$$
\begin{array}{ll}
\text { M } & \text { - measured biochemical marker (LPO level, cata- } \\
& \text { lase activity or SOD activity), } \\
M_{n} & \text { - normalized biochemical marker, } \\
M_{\text {av control }} & \text { - given day's control group average. }
\end{array}
$$


Thus obtained dimensionless data were statistically analyzed using one-way ANOVA and significant differences between the groups were evaluated using post hoc analysis by means of the Tukey's test, at $p<0.05$ selected for statistical significance [7]. All tendencies were plotted basing on the distance-weighted least squares method.

\section{RESULTS}

\section{ABR}

The ABR hearing thresholds of mice exposed to noise and SMF (group I) and exposed to noise only (group II) are presented in Figure 2. Hearing thresholds did not differ significantly between these two study groups either for $4 \mathrm{kHz}$ or $8 \mathrm{kHz}$, although thresholds at $4 \mathrm{kHz}$ were slightly higher for groups exposed to noise and SMF (see Figure 2a).

\section{Biochemical analysis}

All results of biochemical analysis are presented in Tables 1 and 2 .

\section{LPO}

Figure 3 illustrates the alterations in the MDA+HNE level, which is used as the indicator of LPO. There were no significant differences between groups exposed to noise only, SFM only and control for any day of experiment. In contrast, exposure to SMF and noise caused a significant increase in the LPO level compared to control group after 3 days following the exposure to noise (see Figure 3 dash/dot
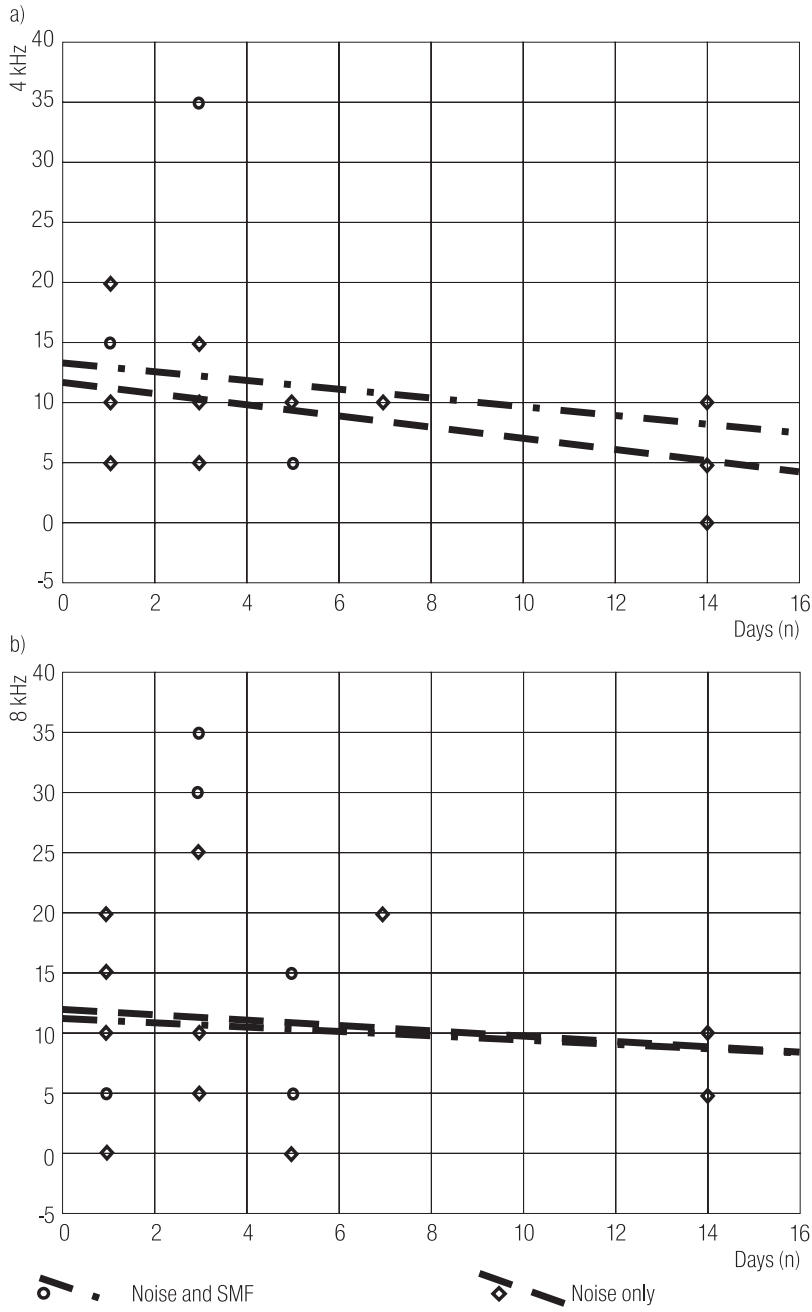

No statistically significant differences between groups were observed.

Fig. 2. Hearing threshold shifts in $\mathrm{C} 57 \mathrm{BL} / 6$ mice exposed to $119 \mathrm{~dB}(\mathrm{~A})$ noise at $4 \mathrm{kHz}$ (a) and $8 \mathrm{kHz}(\mathrm{b})$.

line, confidence coefficient $\mathrm{p}=0.009$; see Table 2), and after 14 days following the exposure to noise $(\mathrm{p}=0.046)$. In the noise-only exposed group, non-significant increase

Table 1. Control group averages of ROS markers in mouse cochlea*

\begin{tabular}{lccccccc}
\hline Group & $\begin{array}{c}\text { Days of } \\
\text { exposure }\end{array}$ & $\begin{array}{c}\text { LPO } \\
\left(\mu \mathrm{M} \times \mathrm{mg}^{-1}\right)\end{array}$ & $\mathrm{SD}$ & $\begin{array}{c}\text { Catalase } \\
\left(\mathrm{nM} \times \mathrm{min}^{-1} \times \mathrm{mg}^{-1}\right)\end{array}$ & $\mathrm{SD}$ & $\begin{array}{c}\text { SOD } \\
\left({\left.\mathrm{U} \times \mathrm{mg}^{-1}\right)}\right.\end{array}$ & $\mathrm{SD}$ \\
\hline IV.1 & 1 & 5.80 & 0.87 & 17.54 & 4.03 & 22.00 & 2.64 \\
IV.3 & 3 & 6.09 & 2.92 & 22.13 & 11.73 & 13.43 & 7.92 \\
IV.5 & 5 & 11.95 & 6.09 & 40.23 & 11.26 & 24.70 & 9.39 \\
IV.7 & 7 & 6.34 & 2.73 & 26.28 & 12.35 & 21.83 & 4.80 \\
IV.14 & 14 & 7.69 & 1.38 & 24.87 & 8.21 & 31.72 & 6.03 \\
\hline
\end{tabular}

$*$ For all groups number of samples analyzed $=8$.

ROS - reactive oxygen species; LPO — lipid peroxidation; SOD — superoxide dismutase.

SD - standard deviation. 
Table 2. Biochemical analysis of ROS markers (relative values, data normalized against given day's control group)*

\begin{tabular}{|c|c|c|c|c|c|c|c|c|c|}
\hline Group & $\begin{array}{l}\text { Days of } \\
\text { exposure }\end{array}$ & Noise & SMF & LPO & SD & Catalase & SD & SOD & SD \\
\hline I.1 & 1 & Y & $\mathrm{Y}$ & 1.16 & 0.16 & 1.85 & 0.97 & 1.15 & 0.29 \\
\hline II.1 & & & $\mathrm{N}$ & 0.87 & 0.29 & 1.37 & 0.33 & 1.11 & 0.33 \\
\hline III.1 & & $\mathrm{N}$ & $\mathrm{Y}$ & 1.08 & 0.25 & 1.05 & 0.35 & 1.41 & 0.25 \\
\hline IV.1 & & & $\mathrm{N}$ & 1.00 & 0.15 & 1.00 & 0.23 & 1.00 & 0.12 \\
\hline I. 3 & 3 & Y & $\mathrm{Y}$ & $\begin{array}{c}1.59 \\
\text { IV.3 }(0.009)^{*}\end{array}$ & 0.32 & $\begin{array}{c}2.54 \\
\text { III.3 }(<0.001)^{*} \\
\text { IV.3 }(<0.001)^{*}\end{array}$ & 0.46 & $\begin{array}{c}2.04 \\
\text { IV.3 }(<0.001)^{*}\end{array}$ & 0.57 \\
\hline II.3 & & & $\mathrm{N}$ & 1.32 & 0.08 & $\begin{array}{c}2.89 \\
\text { III.3 }(<0.001)^{*} \\
\text { IV.3 }(<0.001)^{*}\end{array}$ & 0.54 & 1.58 & 0.64 \\
\hline III.3 & & $\mathrm{N}$ & $\mathrm{Y}$ & 1.41 & 0.53 & $\begin{array}{c}5.34 \\
\text { I.3 }(<0.001)^{*} \\
\text { II.3 }(<0.001)^{*} \\
\text { IV.3 }(<0.001)^{*}\end{array}$ & 2.24 & $\begin{array}{c}1.61 \\
\text { IV.3 }(0.047)^{*}\end{array}$ & 0.44 \\
\hline IV.3 & & & $\mathrm{N}$ & $\begin{array}{c}1.00 \\
\text { I.3(0.009)* }\end{array}$ & 0.48 & $\begin{array}{c}1.00 \\
\text { I.3 }(<0.001)^{*} \\
\text { II.3 }(<0.001)^{*} \\
\text { III.3 }(<0.001)^{*}\end{array}$ & 0.53 & $\begin{array}{c}1.00 \\
\text { I.3 }(<0.001)^{*} \\
\text { III.3 }(0.047)^{*}\end{array}$ & 0.59 \\
\hline I. 5 & 5 & Y & $\mathrm{Y}$ & 0.76 & 0.10 & 0.48 & 0.18 & 0.99 & 0.13 \\
\hline II.5 & & & $\mathrm{N}$ & 0.93 & 0.29 & 1.02 & 0.35 & 1.05 & 0.20 \\
\hline III. 5 & & $\mathrm{~N}$ & $\mathrm{Y}$ & 0.62 & 0.18 & 0.67 & 0.22 & 0.85 & 0.22 \\
\hline IV.5 & & & $\mathrm{N}$ & 1.00 & 0.51 & 1.00 & 0.28 & 1.00 & 0.38 \\
\hline I. 7 & 7 & $\mathrm{Y}$ & $\mathrm{Y}$ & 1.11 & 0.11 & 1.12 & 0.23 & 1.32 & 0.24 \\
\hline II.7 & & & $\mathrm{N}$ & 1.36 & 0.20 & 1.09 & 0.33 & $\begin{array}{c}2.38 \\
\text { IV.7 }(<0.001)^{*}\end{array}$ & 0.38 \\
\hline III.7 & & $\mathrm{N}$ & $\mathrm{Y}$ & 0.88 & 0.21 & 1.07 & 0.18 & 1.27 & 0.15 \\
\hline IV.7 & & & $\mathrm{N}$ & 1.00 & 0.43 & 1.00 & 0.47 & $\begin{array}{c}1.00 \\
\text { II.7 }(<0.001)^{*}\end{array}$ & 0.22 \\
\hline I.14 & 14 & Y & $\mathrm{Y}$ & $\begin{array}{c}1.52 \\
\text { IV.14 }(0.046)^{*}\end{array}$ & 0.27 & 1.26 & 0.26 & 1.41 & 0.33 \\
\hline II.14 & & & $\mathrm{N}$ & 1.03 & 0.29 & 1.06 & 0.39 & 1.12 & 0.22 \\
\hline III.14 & & $\mathrm{N}$ & $\mathrm{Y}$ & 1.02 & 0.22 & 1.06 & 0.41 & 1.22 & 0.32 \\
\hline IV.14 & & & $\mathrm{N}$ & $\begin{array}{c}1.00 \\
\text { I.14 }(0.046)^{*}\end{array}$ & 0.18 & 1.00 & 0.33 & 1.00 & 0.19 \\
\hline
\end{tabular}

ROS — reactive oxygen species; SMF — static magnetic fields; $\mathrm{Y}$ - yes; $\mathrm{N}$ - no. Remaining abbreviations as in Table 1.

For given day's control group averages see Table 1.

* number of the group with the same time of exposure significantly different from the given group (p-value in parentheses)*.

in the MDA+HNE level was seen after 3 and 7 days following the exposure. The most striking difference between the noise-only and noise+SMF-exposed groups was visible after 14 days following the exposures. In the first group LPO level normalized, while in the latter one it rose again to a very high value. 


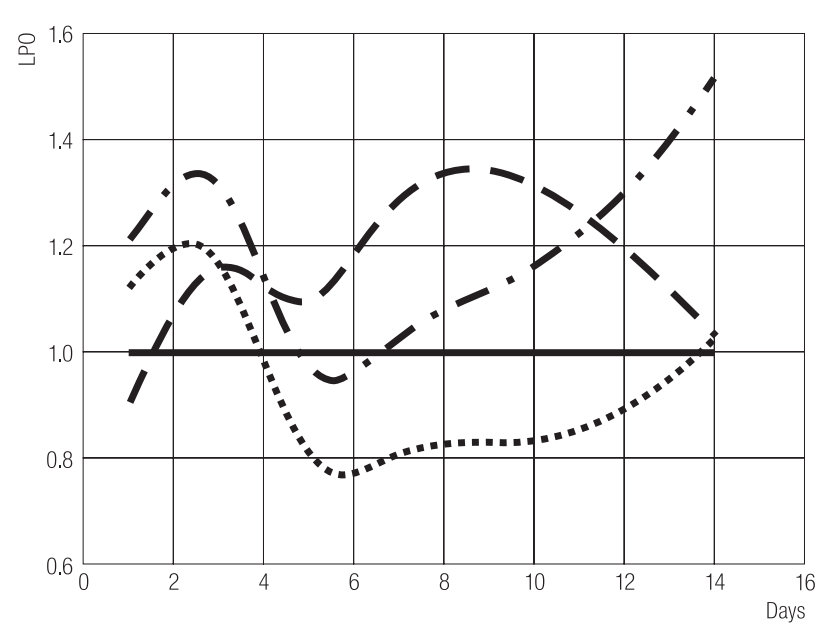

$\longrightarrow$ Noise and SMF

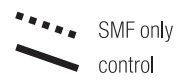

LPO — lipid peroxidation; SMF — static magnetic fields.

Fig. 3. The LPO levels in study subgroups after quotient normalization against given day control group (relative values). Tendencies evaluated by distance-weighted least squares method.

\section{Catalase activity}

The cochlear catalase enzyme activity is given in Figure 4. It shows that after 3 days since the day following exposure to noise/SMF, enzyme activity increased significantly for all exposed groups compared to control ( $p<0.001)$.

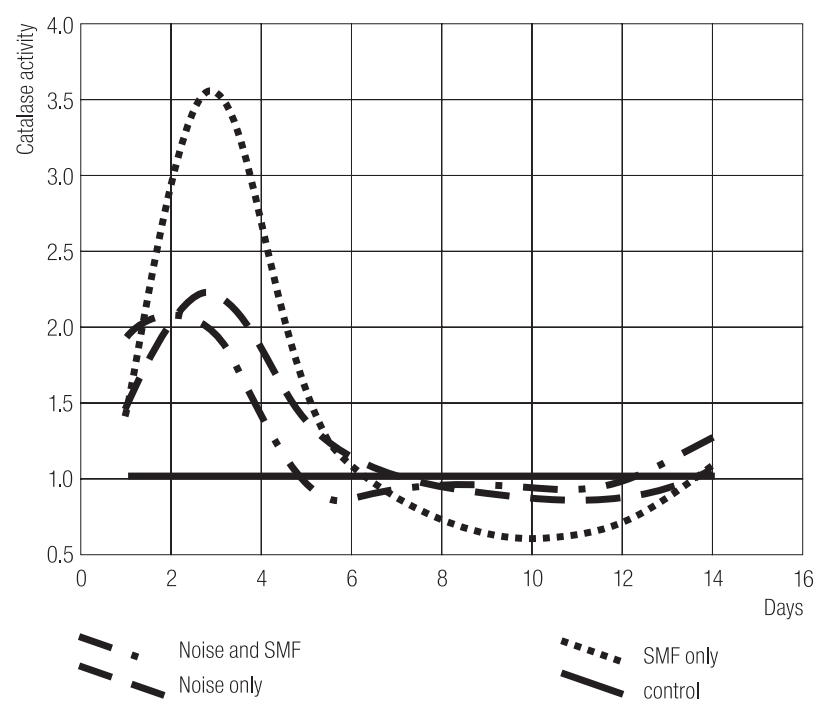

SMF — static magnetic fields.

Fig. 4. Catalase enzyme activity levels in study subgroups after quotient normalization against given day control group (relative values). Tendencies evaluated by distance-weighted least squares method.

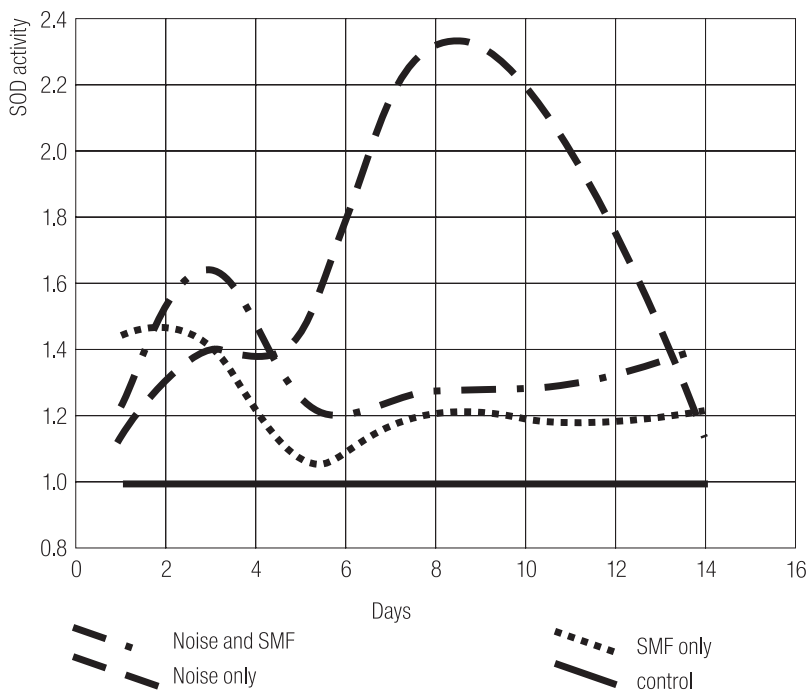

SOD — superoxide dismutase; SMF — static magnetic fields.

Fig. 5. The SOD enzyme activity levels in study subgroups after quotient normalization against given day control group (relative values). Tendencies evaluated by distance-weighted least squares method.

The highest level of catalase activity was observed in the SMF-only exposed group. It was significantly higher than catalase activity in the groups exposed to noise $+\mathrm{SMF}$ and exposed to noise only $(\mathrm{p}<0.001$, see Table 2$)$.

\section{SOD acticity}

The results of SOD activity are shown in Figure 5. In the groups exposed to SMF (groups I and III) a statistically significant increase of SOD activity after 3 days following the day of exposure to noise/SMF was observed relative to the control group ( $p=0.047$ for the group exposed to SMF only, $\mathrm{p}<0.001$ for the group exposed to noise + SMF). At the same time-point the increase in the SOD activity in the noise-only exposed group, although also visible, was not statistically significant. After 7 days following the exposure to noise, a large increase in SOD activity in the group exposed to noise only in comparison with the control group was observed ( $p<0.001$, see Table 2$)$.

\section{DISCUSSION}

ROS among other things play a major role in the mechanism of hearing organ damage induction. The most important ROS localized in cochlear region are: hydroxyl 
radicals, superoxide anion, hydrogen peroxide and nitric oxide [8]. Direct ex vivo measurements of ROS are difficult not only because of limited amount of cochlea material but also because of extremely short lifetime of ROS [9]. Due to this difficulty, some authors use oxidative stress indicators instead of direct ROS measurements.

Exposure to high levels of noise induces ROS overproduction in the cochlea and an increase in LPO levels [10], as peroxidation of membrane proteins is the main effect of the response to oxidative stress [11]. Peroxidation of unsaturated fatty acids leads to the formation of many products, like malondialdehyde (MDA) or 4-hydroxynonenal (4-HNE), which serve as markers of in vivo tissue peroxidation [12]. Thus, LPO levels estimation was chosen as one of markers of ROS in the cochlea. Living organisms developed mechanisms protecting them from oxidative stress. Antioxidant enzymes are major examples of elements of such systems. In our study, activities of two such enzymes (catalase and SOD) were assessed. Catalase reacts with the hydrogen peroxide to catalyze the formation of water and oxygen, while SOD catalyzes the dismutation of superoxide into oxygen and hydrogen peroxide.

In the group exposed to noise only we have observed a tendency to an insignificant increase in LPO levels compared to control group, with a maximum after 7 days. Thereafter (14 days after exposure) LPO levels equalize for both groups. It may prove that, after first week from noise exposure, the protective systems were able to compensate for noise-induced oxidative stress. Exposure to noise accompanied by exposure to SMF further modified LPO levels. For the group exposed to noise+SMF we have observed highest LPO levels after 3 days, then LPO levels decreased to be around control levels to attain finally elevated level after 14 days. This result may indicate that SMF increase ROS quantity in the mouse cochlea after noise exposure. This result confirms the conjecture about SMF influence on oxidative stress processes in the cochlea.

Catalase activity increases in all exposed groups in comparison to control group. Initially this increment was insignificant, but it reached the maximum level as early as after 3 days. The most striking, although not fully explainable observation was particularly high catalase activity at this time point in the group exposed only to SMF. Possible explanation of this phenomenon is offered by the hypothesis presented by Blank and Goodman, who suggest that magnetic fields may increase expression of some proteins $[13,14]$.

We have observed high SOD activity in group exposed to noise in comparison to control group 7 days after exposure. It may point to difference between oxidative processes caused by exposure to noise and exposure to SMF (with varying levels of different ROS causing activation of the production of corresponding enzymes) because for both groups exposed to SMF (I and III) SOD reached maximal activity as soon as after 3 days. This effect is also explainable by Blank and Goodman hypothesis quoted above.

Our results well correspond with other works in this field. Noise-induced threshold shifts [6], increased LPO levels [1,2] and alterations in enzyme activities [3] were also observed by other authors.

The resultant data confirmed our hypothesis that SMF alters noise-induced oxidative processes in mouse cochlea. Noise causes metabolic effects resulting in hearing organ temporary functional disorders and initiates formation of radical pairs - the source of free radicals initiating lipid and protein peroxidation processes. Those radicals, together with radicals formed by oxidative processes, may permanently damage hair cells, thereby causing permanent hearing loss. At the same time, their presence activates protective processes (involving increased activity of antioxidant enzymes) eventually resulting in stable number of damaged cells and permanent hearing threshold. Oxidative mechanism of hearing damage has been generally adopted by the experts $[1,2,15]$. SMF exposure, by affecting the kinetics of radical pairs recombination processes (this mechanism has been also confirmed by some authors [16-18]), influences also oxidative processes continuing in noise-exposed hearing organ. It seems that SMF used in our study works in two directions. First - it promotes increased number of ROS, second - it accelerates activation of antioxidative enzymes. This combination of effects within the model used in this study finally causes no (or very little) changes in hearing loss between groups exposed to noise and SMF, and those exposed only to noise. 
Increased level of LPO after 14 days of exposure to SMF for group exposed to noise and SMF with no differences in antioxidant enzymes activities between groups on this day suggests that with further extension of SMF exposure time (beyond 14 days) hearing organ damage might continue. Further investigations are necessary to confirm or reject that conjecture.

\section{ACKNOWLEDGEMENT}

This study was partially supported with scientific resources by the Polish Ministry of Science and Higher Education (Grants No. 1736/B/P01/2009/36 and 0445/B/P01/2009/36).

\section{REFERENCES}

1. Ohinata Y, Miller JM, Schacht J. Protection from noise-induced lipid peroxidation and hair cell loss in the cochlea. Brain Res 2003;966:265-73.

2. Yamashita D, Jiang HY, Schacht J, Miller JM. Delayed production of free radicals following noise exposure. Brain Res 2004;1019:201-9.

3. Samson J, Wiktorek-Smagur A, Politanski P, Rajkowska E, Pawlaczyk-Luszczynska M, Dudarewicz A, et al. Noiseinduced time-dependent changes in oxidative stress in the mouse cochlea and attenuation by D-methionine. Neuroscience 2008;152(1):146-50.

4.Zmyślony M, Jajte J, Rajkowska E, Szmigielski S. Weak $(5 \mathrm{mT})$ static magnetic field stimulates lipid peroxidation in isolated rat liver microsomes in vitro. Electro Magnetobiol 1998;17(2):109-13.

5. Julicher RH, Sterrenberg L, Haenen GR, Bast A, Noordhoek J. Sex differences in the cellular defence system against free radicals from oxygen or drug metabolites in rat. Arch Toxicol 1984;56(2):83-6.
6. Ou HC, Bohne BA, Harding GW. Noise damage in the C57BL/CBA mouse cochlea. Hear Res 2000;145:111-22.

7. Scheffe H. Analysis of Variance. New York: John Wiley \& Sons Inc.; 1959.

8. Mates JM. Effects of antioxidant enzymes in the molecular control of reactive oxygen species toxicology. Toxicology 2000;153:83-104.

9. Pryor WA. Oxy-radicals and related species: their formation, lifetimes, and reactions. Annu Rev Physiol 1986;48:657-67.

10. Ohinata Y, Miller JM, Altschuler RA, Schacht J. Intense noise induces formation of vasoactive lipid peroxidation products in the cochlea. Brain Res 2000;878:163-73.

11. Halliwell B, Gutteridge JM. Role of free radicals and catalytic metal ions in human disease: an overview. Methods Enzymol 1990;186:1-85.

12. Pompella A. Biochemistry and histochemistry of oxidant stress and lipid peroxidation. Int J Vitam Nutr Res 1997;67: 289-97.

13. Blank M, Goodman R. Electromagnetic initiation of transcription at specific DNA sites. J Cell Biochem 2002;81:689-92.

14. Goodman R, Blank M. Insights into electromagnetic interaction mechanisms. J Cell Physiol 2002;192:16-22.

15. Le Prell CG, Dolan DF, Schacht J, Miller JM, Lomax MI, Altschuler RA. Pathways for protection from noise induced hearing loss. Noise Health 2003;5:1-17.

16. Chignell CF, Sik RH. The effect of static magnetic fields on the photohemolysis in human erythrocytes by ketoprofen. Photochem Photobiol 1998;67(5):591-5.

17. Lai H, Singh NP. Melatonin and N-tert-butyl-a-phenylnitrone blocked 60-Hz magnetic field-induced DNA single and double strand breaks in rat brain cells. J Pineal Res 1997;22:152-62.

18. Jajte J, Grzegorczyk J, Zmyślony M, Rajkowska E. Effect of 7 $m T$ static magnetic field and iron ions on rat lymphocytes: apoptosis, necrosis and free radical processes. Bioelectrochemistry 2002;57:107-11. 